\title{
Aspects of physical and chemical alterations to proteins during food processing - some implications for nutrition
}

\author{
Juliet A. Gerrard ${ }^{1,2,3 *}$, Moritz Lasse ${ }^{1,2,3}$, Justine Cottam ${ }^{2,3,4}$, Jackie P. Healy ${ }^{2,3}$, Sian E. Fayle F, $^{3,5}$, \\ Indira Rasiah ${ }^{3,5}$, Paula K. Brown ${ }^{3}$, Suhaimi Md. BinYasir ${ }^{3,5}$, Kevin H. Sutton ${ }^{5}$ and Nigel G. Larsen ${ }^{1,2,5}$ \\ ${ }^{1}$ Riddet Institute, Massey University, PB 11 222, Palmerston North 4442, New Zealand \\ ${ }^{2}$ Biomolecular Interaction Centre, University of Canterbury, Christchurch, New Zealand \\ ${ }^{3}$ School of Biological Sciences, University of Canterbury, Christchurch, New Zealand \\ ${ }^{4}$ Fonterra Research Centre, Fonterra Co-operative Group Limited, Dairy Farm Road, Palmerston North 4442, New Zealand \\ ${ }^{5}$ Plant and Food Research, Private Bag 4704, Lincoln, New Zealand
}

(Submitted 3 August 2011 - Final revision received 27 October 2011 - Accepted 12 December 2011)

\begin{abstract}
In this paper, we give an overview of our research exploring the impact of physical and chemical processing on food proteins. There are three themes, applied to the proteins of wheat, soya, egg and dairy foods. Firstly, the impact of the Maillard reaction on food proteins is discussed, with a particular focus on how the reactions might be harnessed to manipulate food texture. Secondly, the potential of enzymatic protein-protein crosslinking is considered, especially the enzyme transglutaminase. Thirdly, the broader question of how the aggregation of proteins within a food is altered by chemical and physical modification and how, in turn, this might impact on the overall nutritional quality of the food is considered.
\end{abstract}

Key words: protein-protein crosslinking: Maillard: aggregation: digestibility

\section{Introduction}

The impacts of physical and chemical processing on the structure of food proteins are many and varied, each adding an extra level of complexity to the already complex relationship between protein structure and function. Food proteins are often denatured during processing, so the properties of both the native and denatured state need to be understood. In turn, any chemical derivatisation and the consequent changes in physical structure associated with protein aggregation (itself a complex phenomenon) may impact on the nutritional quality of the food. These complex relationships are illustrated schematically in Fig. 1. In this paper, we consider case studies to illustrate various aspects of these complex relationships. There are three themes, each of which is briefly introduced here, and will then be illustrated by published studies on wheat and soya proteins, together with new work on egg and dairy proteins.

\section{The impact of the Maillard reaction on food proteins}

The Maillard reaction is a complex cascade of chemical reactions, initiated by the deceptively simple condensation of an amine with a carbonyl group, often within a reducing sugar or fat breakdown product ${ }^{(1)}$. Of the many reaction products produced, some remain nutritionally available, but many do not, with the amino acid residue lysine being especially vulnerable ${ }^{(2)}$. Protein crosslinks form an interesting subset of the Maillard reaction products since, in addition to the loss of essential amino acids such as lysine, the covalently bound aggregate is thought to be less accessible to digestive enzymes $^{(3)}$ reducing the digestibility of the protein as a whole. While the precise chemical structures of these crosslinks in food is not completely understood, their presence is well established and we, and others, have studied this phenomenon in wheat and soya foods ${ }^{(4)}$. Herein, we extend these studies to egg and dairy products.

\section{The potential of enzymatic protein-protein crosslinking}

Several enzymes have potential as crosslinking agents for use in food processing ${ }^{(4)}$. Transglutaminase, which catalyses the acyl-transfer reaction between the $\gamma$-carboxyamide group of peptide-bound glutamine residues and various primary amines $^{(5)}$, is of particular interest as the formation of this crosslink does not reduce the nutritional quality of the food ${ }^{(6)}$. The use of this enzyme has been the subject of a series of reviews, 
Fig. 1. Possible interrelationships between food protein structure, protein chemical derivatisation and nutritional value in the final food.

covering both the scientific and patent literature ${ }^{(2,7-9)}$ and is widely considered a versatile food processing aid. We have raised concerns about the use of this enzyme in foods containing wheat proteins, since its side deamidase activity may encourage generation of the epitope responsible for the celiac response upon digestion ${ }^{(10)}$. However, the risk is specific to wheat proteins and does not apply in other food systems.

\section{Aggregation of proteins within a food: chemical and physical modification and the overall nutritional quality of the food}

The complex pathways of protein misfolding and aggregation are increasingly well understood for individual proteins ${ }^{(11)}$ and much of this knowledge can be interpreted in the context of a food matrix. In particular, the complex relationship between chemical derivatisation, protein aggregation and protein digestibility opens up new understandings about how food processing might impact on the fate of food in the gut. Early studies on Maillard protein crosslinking examined the digestibility of a model protein following glycation, observing up to a $30 \%$ reduction in the digestibility of lysozyme by a pepsin-pancreatin solution after glycation with crosslinking agents ${ }^{(12)}$; the digestion process can also be inhibited by the Maillard reaction ${ }^{(3)}$. However, the molecular details of these processes need to be accurately understood to establish the role of chemical derivitisation per se and the subsequent impact on aggregation pathways, some of which may, in themselves, reduce accessibility of digestive enzymes. Herein we present preliminary data which begin to probe these relationships for a model egg white system.

\section{Experimental methods}

Methods for much of the work described in this review have been previously published. Only unpublished methods are included in this section.

\section{Materials}

Unless otherwise stated, all chemicals, reagents and solvents were obtained from Sigma-Aldrich Ltd. (Auckland, New Zealand) or BDH Chemicals Ltd. (Palmerston North, New Zealand) and were of analytical grade. Whey protein isolate (WPI) was WPI895 obtained from Fonterra Research Centre (Palmerston North, New Zealand). Ovalbumin was purified from day-fresh hen egg white by anion exchange chromatography ${ }^{(15)}$.

\section{In vitro incubations}

The methods employed for incubations were based on previously described methods ${ }^{(16-18)}$. For egg white samples, fresh raw hen egg white was homogenised and centrifuged. The supernatant was used as a stock solution for all experiments. Incubations of egg white protein were carried out at varying concentrations, at $80-90^{\circ} \mathrm{C}$, with $200 \mathrm{mM}$ of the following Maillard reaction partners: glucose, fructose, lactose, glutaraldehyde, methylglyoxal. Egg white samples incubated in $\mathrm{dH}_{2} \mathrm{O}$ or in $200 \mathrm{mM} \mathrm{NaCl}$ served as controls. Whey protein isolate - WPI895 $(10 \mathrm{mg} / \mathrm{mL})$ was incubated at $50^{\circ} \mathrm{C}$ with varying concentrations of glutaraldehyde. Each of the samples was made up to a volume of $1 \mathrm{~mL}$ to allow excess sampling. The samples were removed from incubation at specified times frozen in liquid nitrogen and stored at $-80^{\circ} \mathrm{C}$. The zero-time sample and a whey protein frozen control were first dipped in liquid nitrogen before being stored at $-80^{\circ} \mathrm{C}$. A whey protein control (i.e. no crosslinking agent added) was also incubated for the duration of the experiment.

\section{Model food systems}

The standard procedure for tofu ${ }^{(14)}$ and croissant ${ }^{(19,20)}$ manufacture was as previously described. For the model dairy food, an acid-gel system was used. Two protein solutions were made up, the first a $20 \%(\mathrm{w} / \mathrm{w})$ skim milk solution and the second a $2.22 \%$ total solids solution of WPI. Equal amounts of each 
solution (20 g) weighed out into separate containers plus sufficient glutaraldehyde to reach the required concentration $(0.0125 \mathrm{mM}-5 \mathrm{mM})$ were then added to either one or both of the solutions as required. The samples were then stirred for 1 minute, transferred to glass vials, and heated in a water bath at $50^{\circ} \mathrm{C}$ for 30 minutes. Fifteen $\mathrm{g}$ of each of the two protein solutions were then combined and stirred for 1 minute and heated for 30 minutes at $80^{\circ} \mathrm{C}$ in an oil bath. Twenty g of this heated sample were then weighed into a container and acidified with GDL (glucono- $\delta$-lactone) to simulate yoghurt manufacture. The rheological properties of the acid-gel samples were determined using an Anton Paar MCR301 Rheometer (Anton Paar,
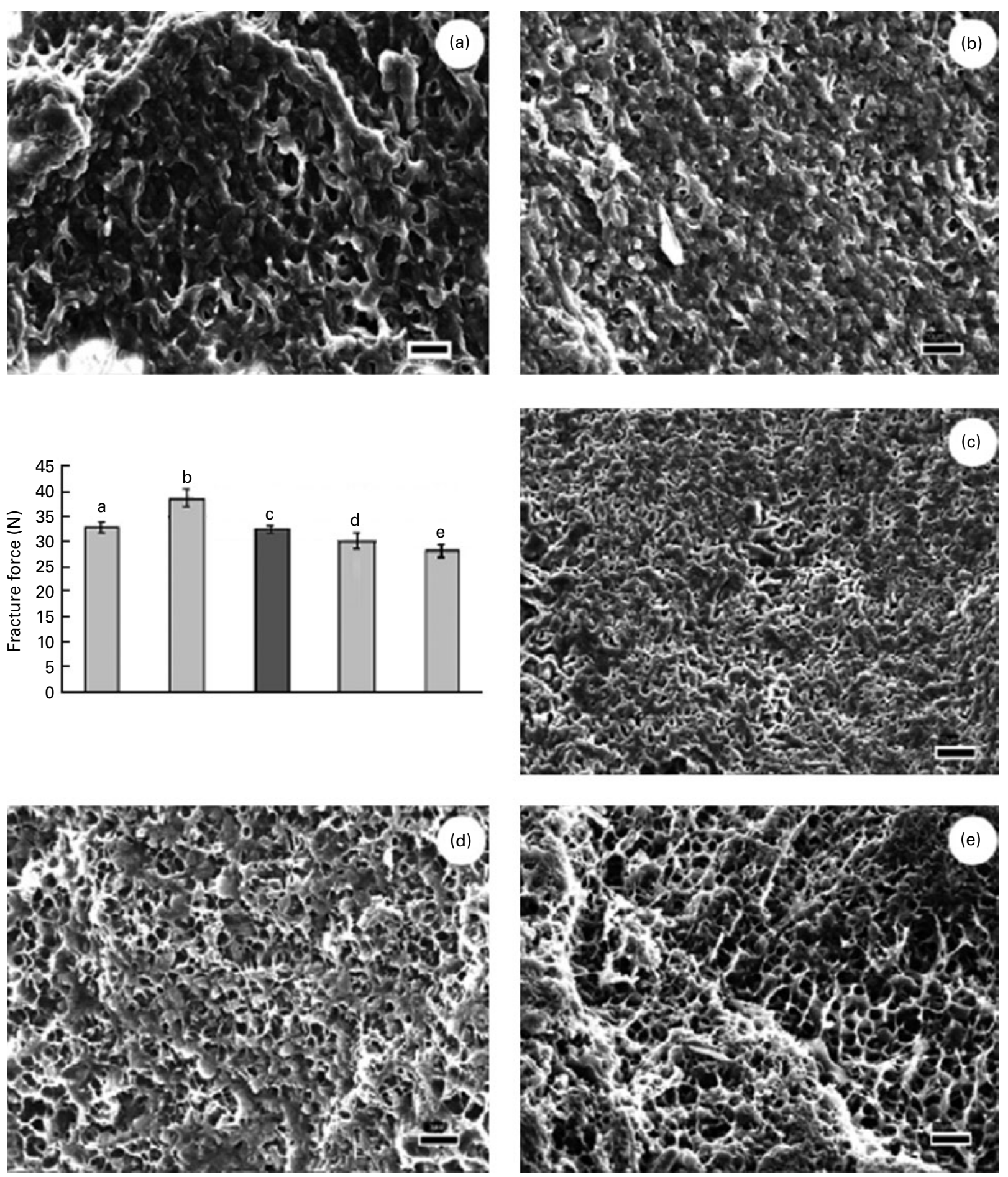

Fig. 2. Treatment of soya milk with glutaraldehyde during the preparation of tofu changes the fracture force and the ultrastructure of the final product. (a) and (b) represent micrographs of 1 and $2 \mathrm{mM}$ glutaraldehyde added before soyamilk boiling. (c) represents the control. (d) and (e) represent micrographs of 1 and $2 \mathrm{mM}$ glutaraldehyde added after soymilk boiling. The images are representative of five replicate experiment. The scale bar represents $10 \mu \mathrm{m}$. For more detail, refer to Yasir et al. ${ }^{(14,18)}$. 


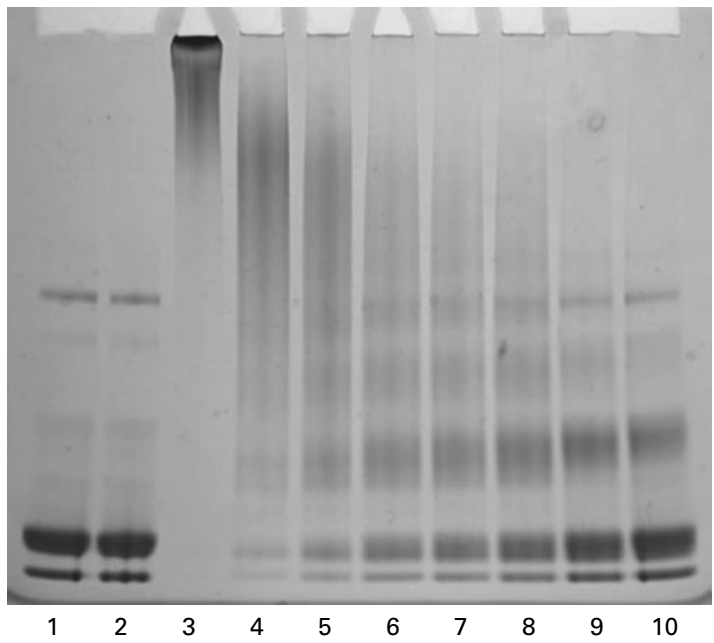

Fig. 3. SDS PAGE analysis of crosslinking of milk proteins. Lanes $1 / 2$, WPI controls containing no glutaraldehyde, non heated (lane 1), heated for the duration of the experiment (lane 2). Lane $3-\mathrm{WPI}+50 \mathrm{mM}$ glutaraldehyde; lane $4-\mathrm{WPI}+20 \mathrm{mM}$ glutaraldehyde; lane $5-\mathrm{WPI}+10 \mathrm{mM}$ glutaraldehyde; lane $6-\mathrm{WPI}+6 \mathrm{mM}$ glutaraldehyde; lane $7-\mathrm{WPI}+5 \mathrm{mM}$ glutaraldehyde; lane 8 - WPI $+4 \mathrm{mM}$ glutaraldehyde; lane $9-\mathrm{WPI}+2 \mathrm{mM}$ glutaraldehyde; lane $10-\mathrm{WPI}+1 \mathrm{mM}$ glutaraldehyde.

Graz, Austria) and in-house methods. The milk samples were monitored for approximately 4 hours, using a $4^{\circ}, 4 \mathrm{~cm}$ diameter cone and plate geometry for all experiments. The required level of GDL (glucono- $\delta$-lactone) was added to the sample, the sample was then stirred for 30 seconds and $1.2 \mathrm{~mL}$ was transferred to the rheometer plate and the cone lowered to give the required gap between the cone and the plate. Three sequential tests were performed in each experiment, where the initial measurements involved monitoring gelation as the milk samples were acidified. Firstly a dynamic time sweep was employed, where a strain of $0 \cdot 1 \%$ at an oscillation frequency of $0 \cdot 1 \mathrm{~Hz}$ was used. The temperature of the sample was maintained at a constant $30^{\circ} \mathrm{C}$ with measurements taken every 60 seconds for the next 3 hours to determine G' (storage modulus). These initial measurements involved monitoring gelation as the milk was acidified. After the time sweep was complete, a temperature sweep of the set gel was performed where the temperature was reduced from $30^{\circ} \mathrm{C}$ to $5^{\circ} \mathrm{C}$ at a rate of $1^{\circ} \mathrm{C} / 15 \mathrm{sec}$ while monitoring the rheological properties at $1^{\circ} \mathrm{C}$ intervals. After the frequency sweep was complete, the deformation rheological properties of the set acid gels at $5^{\circ} \mathrm{C}$ were monitored by progressively increasing the strain at a constant shear rate of $0.005 \mathrm{~s}^{-1}$. The stress was monitored until the gel structure yielded, with measurements taken every second for 5 minutes. In this manner, the fracture stress and fracture strain of the set gel were obtained.

\section{Analytical methods}

The OPA (o-phthaldialdehyde) method was used to measure the lysine availability in water-soluble proteins based on a method from Bertrand-Harb ${ }^{(21)}$. Polyacrylamide Gel Electrophoresis (PAGE) was carried out as previously described ${ }^{(13,14)}$. Scanning Electron Microscopy (SEM) was carried out as previously described $^{(22,23)}$. The egg white samples were prepared by adding $200 \mu \mathrm{L}$ of buffer containing $500 \mathrm{mM}$ cross-linker (controls $\mathrm{dH}_{2} \mathrm{O}$ and $500 \mathrm{mM} \mathrm{NaCl}$ ) to $800 \mu \mathrm{L}$ of day 0 fresh hen egg white. The samples were mixed and then incubated at different temperatures. The samples were then analysed in the same way as the tofu samples, with up to five replications for each treatment.

\section{Differential scanning fluorimetry (DSF)}

DSF was used to analyze ovalbumin stability by measuring the melting temperatures of the purified ovalbumin. One $\mu \mathrm{L}$ of the fluorescent SYPROR Orange Gel Stain (Sigma-Aldrich) ( $250 \times$ concentrated) was used with $4 \mu \mathrm{L}$ of protein sample $(1 \mathrm{mg} / \mathrm{mL})$ and $20 \mu \mathrm{L}$ of buffer. Effects on melting point changes upon incubation of buffered ovalbumin with glucose, fructose, lactose, glutaraldehyde, methylglyoxal were assessed, with $\mathrm{NaCl}$ and $\mathrm{dH}_{2} \mathrm{O}$ as controls. Melting points were measured at ten different protein concentrations $(0 \cdot 2-200 \mathrm{mM}$ final concentration), referenced to a solution containing appropriate amounts of buffer, dye and water. All measurements were made in triplicate and the readings were averaged. Data were recorded on a BioRad IQ5 Multicolor Real-Time PCR Detection System with iCycler (BioRad). For fluorescence measurements, 96 flat well optical plates (Sarstedt) were used with 236707 sealing tape (Nunc ${ }^{\mathrm{TM}}$ ). The plate was sealed and heated from $20^{\circ} \mathrm{C}$ to $95^{\circ} \mathrm{C}$ in increments of $0 \cdot 2^{\circ} \mathrm{C}$, with a 10 second dwell time at each temperature. Fluorescence changes were monitored simultaneously with a charge-coupled device camera. The wavelengths for excitation and emission were 490 and $575 \mathrm{~nm}$, respectively and melting temperatures were determined as the maximum point of inflection using $d \mathrm{RFU} / d \mathrm{t}^{(24)}$.

\section{Small Angle X-ray Scattering (SAXS)}

Scattering experiments of treated ovalbumin samples were carried out at the Australian Synchrotron in Melbourne. For the beamline setup, a camera length of $3334.83 \mathrm{~mm}$ was chosen and the experiments were carried out at a wavelength of $1.03320 \AA$. A Pilatus M1 detector $(981 \times 1043$ pixels $)$ was

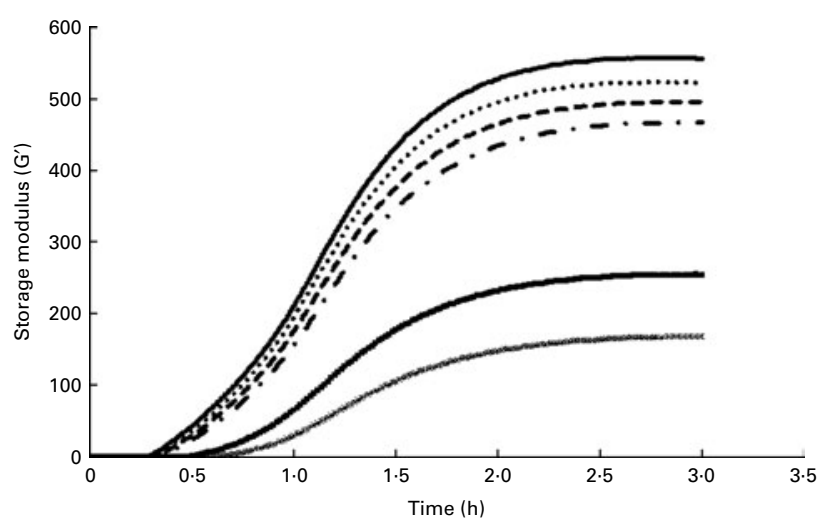

Fig. 4. Plot of gelation curves obtained with the whey protein solution (WPI) pre-crosslinked with glutaraldehyde in acid-gel experiments. Storage modulus $\left(\mathrm{G}^{\prime}\right)$ as a function of time (hrs). — WPI Control (no glutaraldehyde), ...... WPI (0.125 mM glutaraldehyde), ...- WPI (0.25 mM glutaraldehyde), -. WPI (0.5 mM glutaraldehyde), $\rightarrow$ WPI (1 mM glutaraldehyde), $\rightarrow$ WPI (2 $\mathrm{mM}$ glutaraldehyde). 


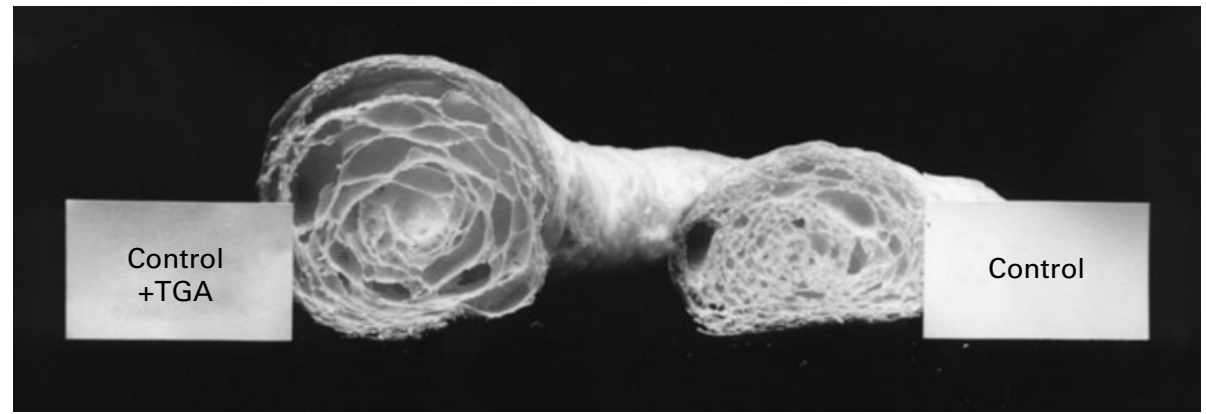

Fig. 5. Transglutaminase has a dramatic impact on croissant pastry. In this image, the control croissant is made to a standard recipe whilst the croissant on the left is made to the same recipe, with the addition of transglutaminase. Unfortunately, doubts have been cast on the safety of transglutaminase for the use in wheat-based products. For more details refer previous paper ${ }^{(19,10)}$.

used. The measured q-range $\left(\mathrm{q}=4^{*} \pi^{*} \sin (\nabla) / \lambda\right)$ ) was $0 \cdot 005-$ $0 \cdot 287 \AA^{-1}$. Ovalbumin samples of different concentrations were loaded into a glass capillary and blanked against the respective buffers containing no protein. An exposure time of $20 \times 1$ second was chosen.

\section{Digestibility assays}

An in vitro model of human digestion was used to study protein digestibility, based on previous studies ${ }^{(25-27)}$. Firstly, egg white samples were subjected to simulated mastication in a glass homogeniser. To $560 \mu \mathrm{L}$ of $\mathrm{dH}_{2} \mathrm{O}, 50 \mathrm{mg}$ of homogenised sample were added and mixed. Subsequently amylase digestion was carried out to mimic polysaccharide breakdown in the mouth by adding $2 \mu \mathrm{L}$ of a $10 \%$ amylase stock (Sigma No.: A3176) and incubation for 5 minutes at $37^{\circ} \mathrm{C}$. The $\mathrm{pH}$ was then adjusted to 1.5 by adding $20 \mu \mathrm{L} 1 \mathrm{M}$ $\mathrm{HCl}$ to simulate the acidic stomach environment. Following acidification, $20 \mu \mathrm{L}$ of $10 \%$ porcine pepsin (Sigma No.: P7000) stock solution was added to the sample and the sample was incubated for 30 minutes at $37^{\circ} \mathrm{C}$. Samples were then neutralised using $40 \mu \mathrm{L}$ of $\mathrm{NaHCO}_{3}$ to stop any further pepsin digestion. To simulate small intestinal digestion, porcine pancreatin (Sigma No.: P1750) was chosen. The $\mathrm{pH}$ of the sample was adjusted to 7.5 using $200 \mu \mathrm{L}$ of $167 \mathrm{mM}$ $\mathrm{KH}_{2} \mathrm{PO}_{4} \mathrm{pH}$ 7.5. Subsequently $100 \mu \mathrm{L}$ of $2 \cdot 5 \%$ pancreatin stock solution was added and samples were digested for 2 hours at $37^{\circ} \mathrm{C}$. Aliquots were taken after each digestion step and analysed using PAGE to analyse the amount of protein digested.

\section{Results and Discussion}

\section{The impact of the Maillard reaction on food proteins}

We have previously published research on the impact of the Maillard reaction, and particularly the resulting protein crosslinking, on food texture in wheat and soya foods. Introduction of protein crosslinks into baked products has been shown to improve a number of properties that are valued by the consumer ${ }^{(13,19)}$. In situ studies revealed that following addition of glutaraldehyde to dough, the albumin and globulin fractions of the extracted wheat proteins were crosslinked ${ }^{(28)}$. Inclusion of glutaraldehyde during bread preparation resulted in the formation of a dough with an increased dough relaxation time, relative to the commonly used flour improver ascorbic $\operatorname{acid}^{(29)}$. These results confirmed that chemical crosslinks are important in the process of dough development, and suggest that they can be introduced via Maillard type chemistry.

In tofu, Kaye et al. ${ }^{(30)}$ reported that following incubation with glucose, a Maillard network formed within the internal structure of tofu, resulting in a loss in tofu solubility and a reduction in tofu weight loss. Furthermore, Kwan and Easa $^{(31)}$ employed low levels of glucose for the preparation of retort tofu, which resulted in the production of firmer tofu product. Changes in tofu structure have also been observed in our laboratory when including glutaraldehyde, glyceraldehyde or formaldehyde in tofu preparation ${ }^{(14,18)}$. However, these results suggested that protein crosslinking agents may change the functional properties of tofu via noncrosslinking modifications of the sidechains of the amino acid residues, perhaps by changing their isoelectric point and gelation properties ${ }^{(32)}$. This illustrates the challenge of attributing specific impacts on the quality of food with

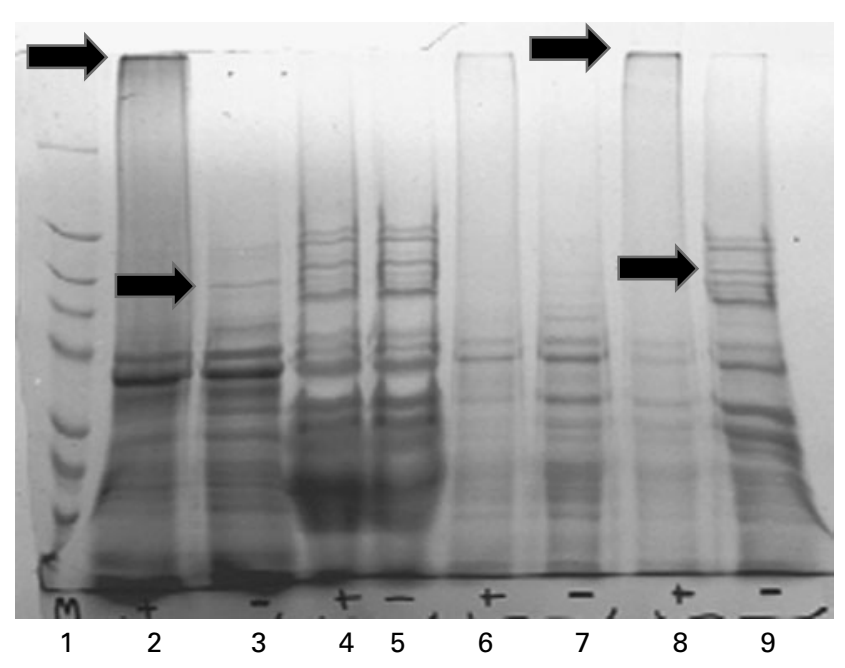

Fig. 6. SDS-PAGE analysis of proteins extracted from croissant pastry. Lane 1, molecular weight markers. Lanes $2 / 3$, albumin and globulin fraction with/without transglutaminase; lanes $4 / 5$, gliadin fraction with/without transglutaminase; lanes $6 / 7$ soluble glutenin fraction with/without transglutaminase; lanes $8 / 9$ insolble glutenin fraction with/without transglutaminase. Arrows highlight crosslinked proteins that correspond to an increase in product quality. For more details see Rasiah et al. ${ }^{(35)}$. 
particular introduced changes, especially when using chemistry as complicated as Maillard chemistry, which results in many different products. Nevertheless, the impact of the Maillard reaction on both the ultrastructure of the tofu and the functional properties, as monitored by fracture force measurements, was clearly evident (Fig. 2). The extent to which these changes impact on the nutritional qualities of the tofu or wheat based products has yet to be investigated.

The covalent polymerisation of milk during food processing has also been reported ${ }^{(33)}$. This phenomenon was shown to be sugar dependent, as determined in model studies with $\beta$-casein. Further, pentosidine formation paralleled protein aggregation over time at $70^{\circ} \mathrm{C}^{(34)}$, suggesting that Maillard chemistry plays an active role. Recent results in our laboratory are illustrated in Fig. 3, in which whey protein isolate was incubated with various concentrations of glutaraldehyde and the resulting conjugates analysed by PAGE. Loss of lysine residues was assessed using the OPA method. Results indicated that $1 \%$ whey protein isolate incubated with $2 \mathrm{mM}$ glutaraldehyde at $50^{\circ} \mathrm{C}, \mathrm{pH} 7$ sustained a loss of $20 \%$ of the available lysine residues during the course of the incubation, which is consistent with the crosslinking pattern observed (Fig. 3).
When this Maillard chemistry takes place in a model food system, such as an acid gel (Fig. 4), then there is a clear change in the functional properties of the proteins in solution. In particular, the storage modulus is seen to decrease with an increased concentration of glutaraldehyde. This pattern could either be attributed to the crosslinking pattern observed in Fig. 3 or, analogous to the tofu case, may correspond to changes in physicochemical properties resulting from noncrosslinking protein glycation. Further work is underway to investigate these possibilities.

\section{The potential of enzymatic protein-protein crosslinking}

The enzyme transglutaminase has been explored in many different foods. We have investigated its potential as an additive in wheat-based foods, and found a particularly dramatic improvement in the quality of croissant pastry was afforded by the addition of a commercial preparation of the enzyme (Fig. 5). An analysis of the proteins extracted from the pastry of croissants treated with transglutaminase showed an average of $5 \%$ lysine residues lost, with a small degree of crosslinking observed in the albumin and globulin and insoluble glutenin
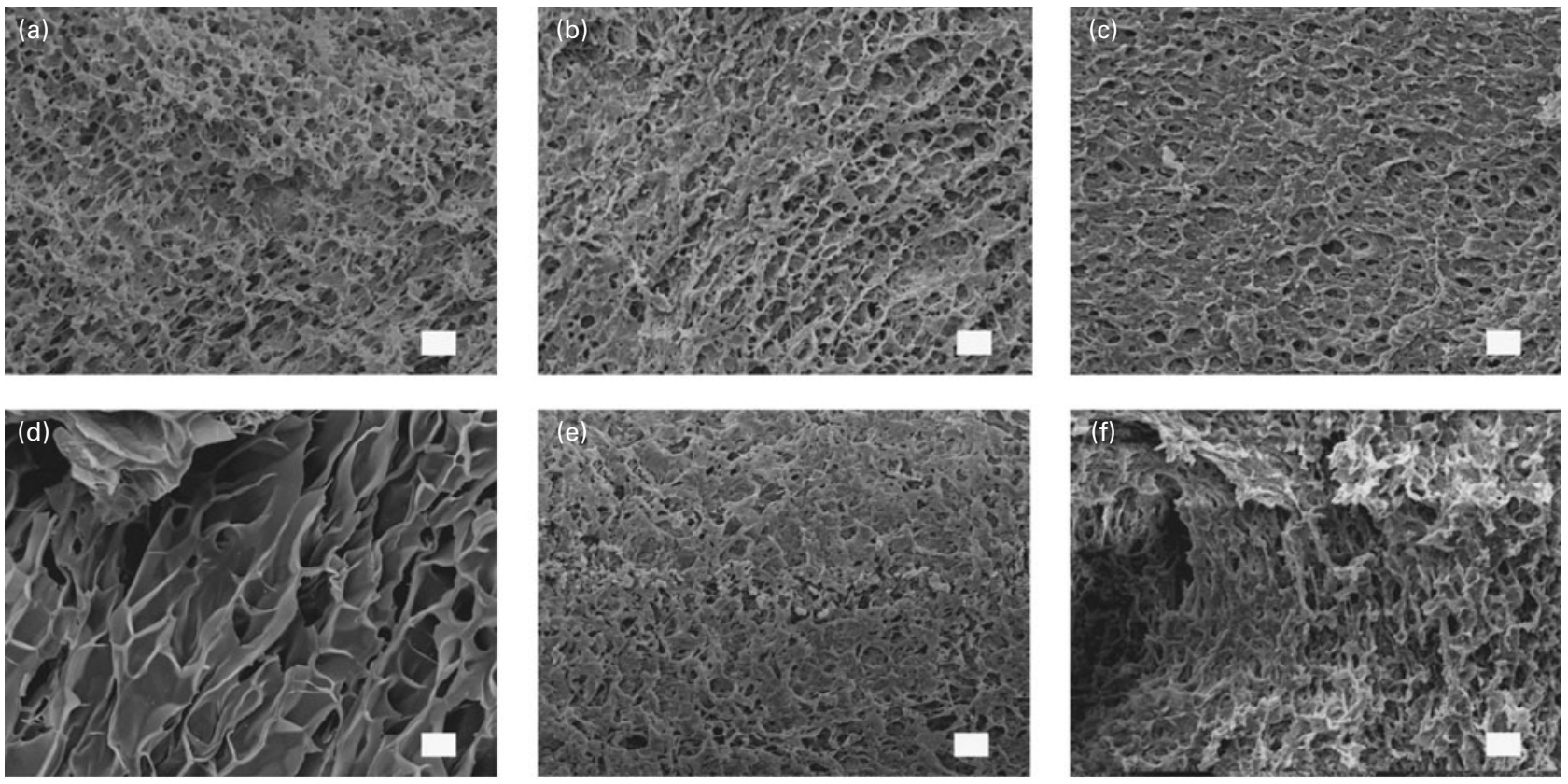

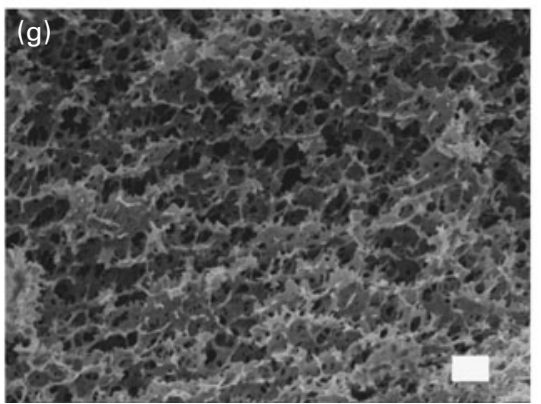

Fig. 7. SEM micrographs of egg white in the presence of different glycation partners and controls. From top left to bottom: Egg white incubated for $5 \mathrm{~h}$ in the presence of (a) $100 \mathrm{mM}$ glucose, (b) $100 \mathrm{mM}$ fructose, (c) $100 \mathrm{mM}$ lactose, (d) $100 \mathrm{mM}$ glutaraldehyde, (e) $100 \mathrm{mM}$ methylglyoxal, (f) $100 \mathrm{mM}$ NaCl, (g) water. The scale bar is $10 \mu \mathrm{m}$. 
Table 1. Melting temperature $\left(T_{M}\right)$ for ovalbumin incubated with a variety of crosslinking agents during the melting experiment from $20^{\circ} \mathrm{C}$ to $95^{\circ} \mathrm{C}$. Measurements were made via differential scanning fluorimetry according to the method of Ericsson et al. 2006

\begin{tabular}{lccccccc}
\hline Reactant & Glutaraldehyde & Methylglyoxal & Glucose & Fructose & Lactose & $\mathrm{NaCl}$ & $\mathrm{dH}_{2} \mathrm{O}$ \\
\hline $\mathrm{T}_{\mathrm{M}}$ & $55.7 \pm 3.0$ & $63.4 \pm 3.0$ & $78.6 \pm 0.2$ & $78.5 \pm 0.2$ & $78.6 \pm 0.2$ & $77.1 \pm 0.2$ & $78.3 \pm 0.2$ \\
\hline
\end{tabular}

fractions (Fig. 5). From this and other studies ${ }^{(35)}$, it was concluded that only a few crosslinks in specific protein fractions were sufficient to confer the improvement in pastry quality ${ }^{(19)}$.

Later work by our group and others has demonstrated that soya products may also benefit from the introduction of transglutaminase. The enzyme is reported to enhance the quality of tofu made from old soya crops, giving a product with increased water holding capacity, a good consistency, a silky and firmer texture and one that is more robust in the face of temperature change ${ }^{(36,37)}$. Transglutaminase has also been used to incorporate soya protein into new products, such as chicken sausages ${ }^{(38)}$. In our work, treatment with transglutaminase (a)

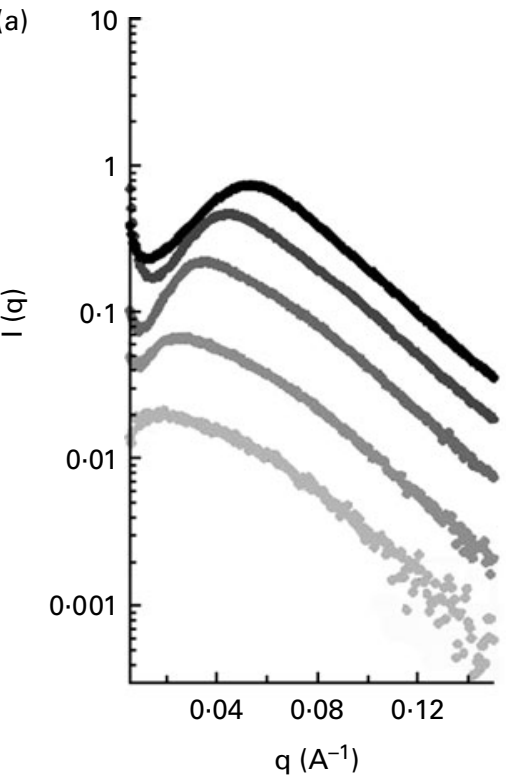

(c)

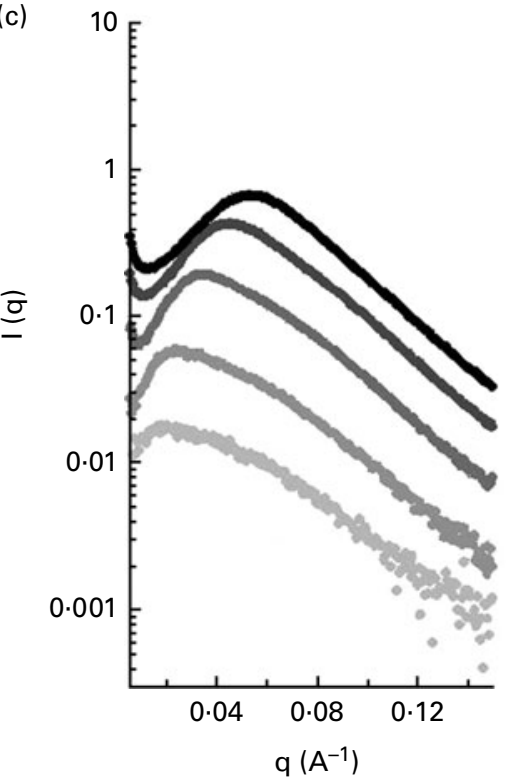

(b)

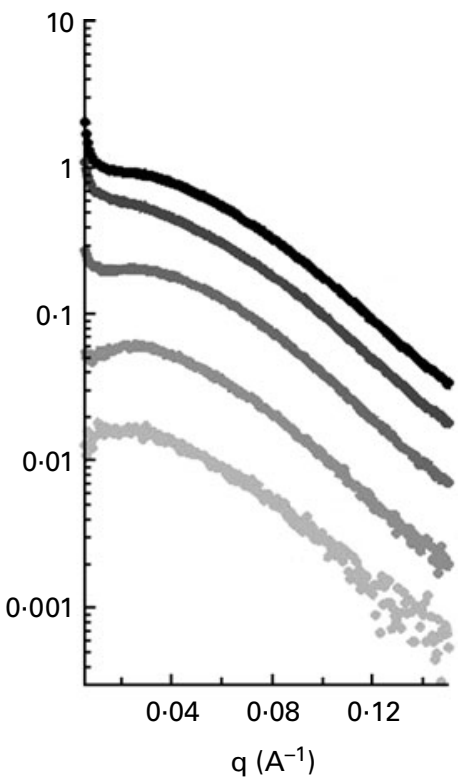

(d)

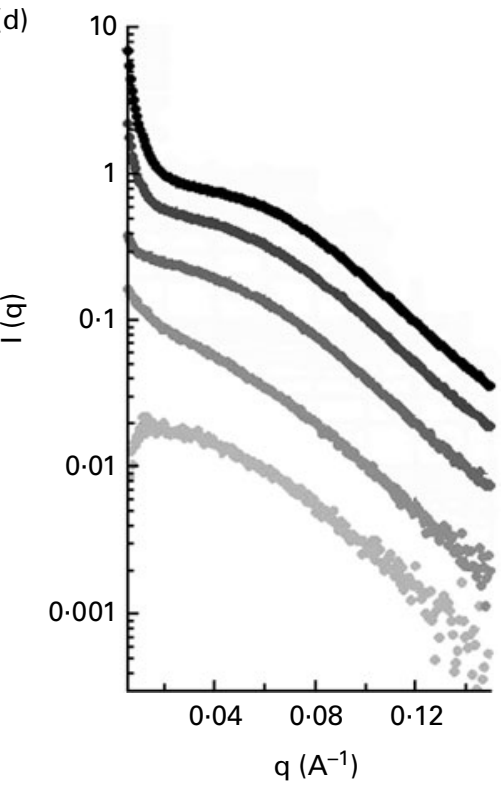


produced a firmer tofu, with a significantly increased fracture force. SEM revealed that the microstructures of the samples were consistent with the changes in fracture force, in an analogous manner to the glutaraldehyde treated tofu, shown in Fig. $2^{(14,18)}$. The firmness varied according to both the concentration of enzyme added and the point of addition in the manufacturing process, suggesting opportunities for customising tofu by simple alterations in the timing of transglutaminase addition. However, when proteins were extracted from the tofu matrix after treatment with transglutaminase in situ, little, if any, cross-linking occurred as assessed by PAGE (Fig. 6). This suggested that the change in functional properties afforded by addition of transglutaminase to tofu is perhaps due to a side reaction of the enzyme, hydrolysis of glutamine residues to glutamate, as previously postulated by Babiker ${ }^{(39)}$. Since water is abundant during tofu manufacture, it is likely that transglutaminase-promoted hydrolysis of glutamine residues of the protein to glutamate residues could occur. The resulting change in isoelectric point of the soya proteins would be predicted to change the gelation and microstructure of the proteins ${ }^{(40)}$. It would also suggest that in food systems where the side reaction out-competes the crosslinking reaction, the nutritional quality of the food is likely to be diminished, in contrast to the work of Seguro et al. ${ }^{(6)}$, where the lysine residue was protected from Maillard chemistry by the crosslinking process, and later released as a bioavailable residue. Further work is needed to test this hypothesis in this, and other, systems in which side reactions of transglutaminase are implicated as important for changing the properties of food ${ }^{(10)}$.

\section{Aggregation of proteins within a food: chemical and} physical modification and the overall nutritional quality of the food

The results thus far presented in sections 1 and 2 hint at a relationship between chemical modification of protein side chains and the physical process of protein aggregation. Either or both of these may impact on both food structure and the nutritional quality of the food in question. To examine these relationships (Fig. 1), we are exploring model egg white proteins. Specifically, we aim to unravel the relationship between chemical modification, aggregation and nutritional quality. Some preliminary data from early experiments are presented here. In Fig. 7, SEM micrographs of egg white treated with various reaction partners are presented. Some marked differences were observed from the control protein, especially upon treatment with glutaraldehyde which produces an open mesh-like structure compared to the control (Fig. 6D).

This change in structure is concomitant with a change in the melting temperatures of the derivatised protein, as seen in Table 1. It is interesting to note that the two most effective crosslinking agents ${ }^{(41)}$ also produce the lowest melting temperature for the proteins.

To probe the impact of chemical modification on physical aggregation, we have initiated a small angle $\mathrm{x}$-ray scattering study on the early stages of ovalbumin aggregation, with and without modification by a Maillard reactive molecule. Figure 8 shows the results of these early experiments, illustrating that modification by methyl glyoxal alters the scattering data, indicative of an altered aggregation pathway and validating the technique as a method to explore these differences. Further analysis is underway to inform future experiments to reveal specific changes to particle size as a function of modification and time.

In concert with these measurements, a parallel study of digestibility of ovalbumin is being undertaken, some results from which are illustrated in Fig. 9. In the first instance, different cooking methods were employed and the digestibility of the samples compared. In agreement with literature data $^{(42-45)}$, all cooking methods rendered the egg white protein more digestible than the raw protein (data not shown). Repeating these experiments with Maillard reactive reagents (a)

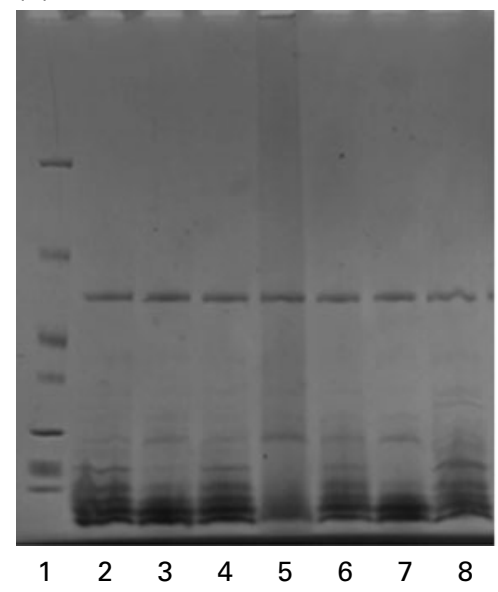

(b)

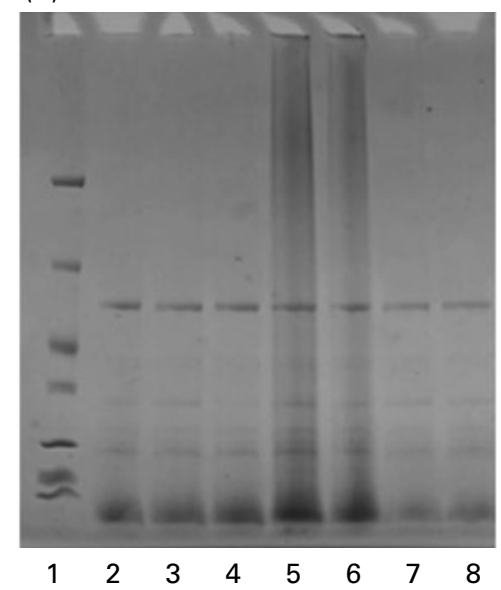

(c)

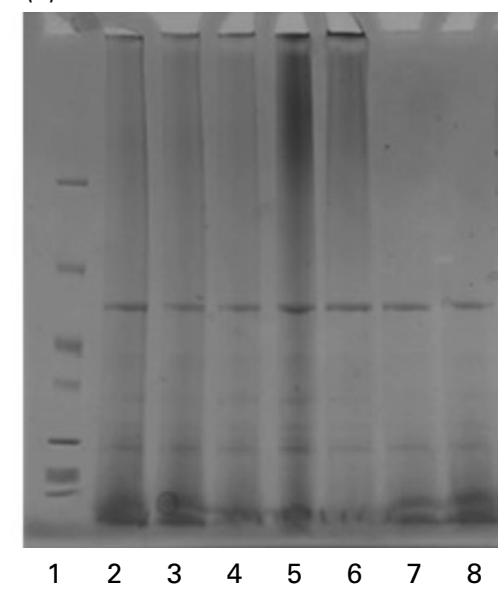

Fig. 9. Egg white + crosslinkers heated at $90^{\circ} \mathrm{C}$ for (a) 0 hours, (b) 5 hours, (c) 24 hours and then subjected to an in vitro model of human digestion. $1-8$ : 1) protein marker, 2) egg white $+200 \mathrm{mM}$ glucose, 3) egg white $+200 \mathrm{mM}$ fructose, 4) egg white $+200 \mathrm{mM}$ lactose, 5) egg white $+200 \mathrm{mM}$ glutaraldehyde, 6 ) egg white $+200 \mathrm{mM}$ methylglyoxal, 7) egg white $+\mathrm{dH}_{2} \mathrm{O}$, 8) egg white $+200 \mathrm{mM} \mathrm{NaCl}$. The protein smear in the lanes corresponds to crosslinked, non digested high molecular weight protein. The visible distinct bands are enzymes from the pancreatin mixture and correspond to amylase, trypsin, chymotrypsin. 
reveals some greater variation, and in particular the crosslinked samples are harder to digest, although quite harsh conditions are required before these differences are manifest. These observations are consistent with previous reports ${ }^{(46)}$ and future work aims to unravel whether these differences are due to the chemical or physical modifications to the protein.

\section{Concluding comments and future directions}

The various case studies presented here illustrate the complexities in the relationship between chemical and physical modification of food proteins, and their potential effects on digestion. Protein crosslinking, whether chemically or enzymatically induced, is likely to reduce digestibility, although in the particular case of transglutaminase-catalysed crosslinking the reverse situation may be true in some food systems. In this case, transglutaminase treatment is likely to improve nutritional quality, especially in cases where high reducing sugar content may otherwise lead to loss of lysine residues through Maillard chemistry.

The Maillard reaction of food proteins, or protein glycation, involves a large number of non-crosslinking products, many of which may have an impact on both the nutritional and functional properties of food.

In general, the interplay between chemical modification of proteins and their physical aggregation properties and how this might impact on food quality, in terms of both sensory qualities and nutritional value, warrants further investigation. Methods such as mass spectrometry and SAXS, in tandem with in vitro and in vivo assays of protein digestibility may prove very valuable in untangling these relationships.

\section{Acknowledgements}

This work has been funded from a variety of sources over several years, including the following contracts: Dairy Ingredient Solutions for Nutritional Vitality (DRIX0801); Bakery Products \& Beverages (C02408); Advanced Biological Materials (C02X0001, C02X0204); "Cereal Based Food" (C02803); scholarship to SY from the Malaysian government and the Riddet Institute, Palmerston North, New Zealand. JAG: project leader, wrote manuscript; NGL: co-project leader; ML: carried out egg work and SAXS experiements; JC: carried out acid gel experiments on milk proteins; JPH: assisted with electrophoretic analysis and lab management; SEF: completed early work on wheat proteins, including croissant experiment; IR: completed later work on wheat proteins using enzymatic crosslinking; PKB: completed later work on wheat proteins using Maillard chemistry; SY: completed work on soy proteins; KHS contributed to supervision of several students and provided expertise in protein analysis. The authors state that there are no conflicts of interest.

\section{References}

1. Fayle SE \& Gerrard JA (2002) The Maillard Reaction [PS Belton, editor]. Cambridge: The Royal Society of Chemistry.
2. Friedman M (1996) The impact of the Maillard reaction on the nutritional value of food proteins. In The Maillard reaction: consequences for the chemical and life sciences, p. 119 [R Ikan, editor]. New York: John Wiley and Sons.

3. Friedman M (1999) Chemistry, biochemistry, nutrition, and microbiology of lysinoalanine, lanthionine, and histidinoalanine in food and other proteins. J Ag Food Chem 47, 1295-1319.

4. Cottam JRA \& Gerrard JA (2012) Protein crosslinking in food - structure, applications, implications for health and food safety. In Food Biochemistry and Food Processing, 2nd ed., Chapter 10, pp. 207-223. [YH Hui, editor]. USA: Blackwell.

5. Zhu Y, Bol J, Rinema A, et al. (1995) Microbial transglutaminase. A review of its production and application in food processing. Appl Microbiol Biotech 44, 277-282.

6. Seguro K, Kumazawa Y, Kuraishi C, et al. (1996) The epsilon(gamma-glutamyl)lysine moiety in crosslinked casein is an available source of lysine for rats. J Nutr 126, 2557-2562.

7. Jaros D, Partschefeld C, Henle T, et al. (2006) Transglutaminase in dairy products: Chemistry, physics, applications. J Text Stud 37, 113-155.

8. Kuraishi C, Yamazaki K \& Susa Y (2001) Transglutaminase: Its utilization in the food industry. Food Rev Int 17, 221-246.

9. Nielsen PM (1995) Reactions and potential industrial applications of transglutaminase - review of literature and patents. Food Biotech 9, 119-156.

10. Gerrard JA \& Sutton KH (2005) Addition of transglutaminase to cereal products may generate the epitope responsible for coelic disease. Trends Food Sci Technol 16, 510-512.

11. Luheshi LM, Crowther DC \& Dobson CM (2008) Protein misfolding and disease: from the test tube to the organism. Curr Opin Chem Biol 12, 25-31.

12. Kato H, Chuyen NV, Utsunomiya N, et al. (1986) Changes of amino acids composition and relative digestibility of lysozyme in the reaction with $\alpha$-dicarbonyl compounds in aqueous system. J Nutr Sci Vitaminol 32, 55-65.

13. Gerrard JA, Fayle SE, Wilson AJ, et al. (1998) Dough properties and crumb strength of white pan bread as affected by microbial transglutaminase. J Food Sci 63, 472-475.

14. Yasir S, Bin Md, Sutton KH, et al. (2007) The impact of transglutaminase on soya proteins and tofu texture. Food Chem 104, 1491-1501.

15. de Groot J \& de Jongh HH (2003) The presence of heat-stable conformers of ovalbumin affects properties of thermally formed aggregates. Protein Eng 16, 1035-1040.

16. Fayle SE, Gerrard JA, Simmons L, et al. (2000) Crosslinkage of proteins by dehydroascorbic acid and its degradation products. Food Chem 70, 193-198.

17. Gerrard JA, Brown PK \& Fayle SE (2002) Maillard crosslinking of food proteins I: the reaction of glutaraldehyde, formaldehyde and glyceraldehydes with ribonuclease. Food Chem 79, 357-363.

18. Yasir S, Bin Md, Sutton KH, et al. (2007) The impact of Maillard cross-linking on soya proteins and tofu texture. Food Chem 104, 1502-1508.

19. Gerrard JA, Newberry MP, Ross M, et al. (2000) Pastry lift and croissant volume as affected by microbial transglutaminase. J Food Sci 65, 312-314.

20. Gerrard JA, Fayle SE, Brown PA, et al. (2001) Effects of microbial transglutaminase on the wheat proteins of bread and croissant dough. J Food Sci 66, 782-786.

21. Bertrand-Harb C, Nicolas MG, Dalgalarrondo M, et al. (1993) Determination of alkylation degree by 3 colorimetric methods and amino acid analysis - a comparative study. Sci Aliments 13, 577-584. 
22. Kang IJ (1994) Gelation and gel properties of soybean glycinin in a transglutaminase-catalyzed system. J Agric Food Chem 42, 159.

23. Goldstein JI, Newbury DE, Echlin P, et al. (1992) Scanning Electron Microscopy and X-Ray Microanalysis. New York: Plenum Press.

24. Ericsson UB, Hallberg BM, DeTitta GT, et al. (2006) Thermofluor-based high-throughput stability optimization of proteins for structural studies. Anal Biochem 357, 289-298.

25. Fu T, Abbott UR \& Hatzos C (2002) Digestibility of food allergens and nonallergenic proteins in simulated gastric fluid and simulated intestinal fluid - a comparative study. J Agric Food Chem 50, 7154-7160.

26. Kim EHJ, Petrie JR, Motoi L, et al. (2008) Effect of structural and physicochemical characteristics of the protein matrix in pasta on in vitro starch digestibility. Food Biophys 3, 229-234.

27. Pharmacopeia US (2009) National formulary. USP 27.

28. Gerrard JA, Brown PK \& Fayle SE (2003) Maillard crosslinking of food proteins II: the reactions of glutaraldehyde, formaldehyde and glyceraldehyde with wheat proteins in vitro and in situ. Food Chem 80, 35-43.

29. Gerrard JA, Brown PK \& Fayle SE (2003) Maillard crosslinking of food proteins III: the effects of glutaraldehyde, formaldehyde and glyceraldehyde upon bread and croissants. Food Chem 80, 45-50.

30. Kaye YK, Easa AM \& Ismail N (2001) Reducing weight loss of retorted soya protein tofu by using glucose- and microwave-pre-heating treatment. Int J Food Sci Technol 36, 387-392.

31. Kwan SW \& Easa AM (2003) Comparing physical properties of retort-resistant glucono- $\delta$-lactone tofu treated with commercial transglutaminase enzyme or low levels of glucose. Food Sci Technol 36, 643-646.

32. Fayle SE, Healy JP, Brown PA, et al. (2001) Novel approaches to the analysis of the Maillard reaction of proteins. Electrophoresis 22, 1518-1525.

33. Singh H \& Latham J (1993) Heat stability of milk: aggregation and dissociation of protein at ultra-high temperatures. Int Dairy J 3, 225-235.
34. Pellegrino L, van Boekel M, Gruppen H, et al. (1999) Heatinduced aggregation and covalent linkages in $\beta$-casein model systems. Int Dairy J 9, 255-260.

35. Rasiah IA, Sutton KH, Low FL, et al. (2005) Crosslinking of wheat dough proteins by glucose oxidase and the resulting effects on bread and croissants. Food Chem 89, 325-332.

36. Kuraishi C, Yamazaki K \& Susa Y (2001) Transglutaminase: Its utilization in the food industry. Food Rev Int 17, 221-224.

37. Soeda $\mathrm{T}$ (2003) Effects of microbial transglutaminase for gelation of soya protein isolate during cold storage. Food Sci Technol Res 9, 65-169.

38. Muguruma M, Tsuruoka K, Katayama K, et al. (2003) Soybean and milk proteins modified by transglutaminase improves chicken sausage texture even at reduced levels of phosphate. Meat Sci 63, 191-197.

39. Babiker EE (2000) Effect of transglutaminase treatment on the functionl properties of native and chymotrypsin-digested soya protein. Food Chem 70, 139-145.

40. Dickinson E (1997) Enzymic crosslinking as a tool for food colloid rheology control and interfacial stabilization. Trends Food Sci Technol 8, 334-339.

41. Meade SJ, Miller AG \& Gerrard JA (2003) The role of dicarbonyl compounds in non-enzymatic crosslinking: a structure-activity study. Bioorg Med Chem Lett 11, 853-862.

42. Evenepoel P, Geypens B, Luypaerts A, et al. (1998) Digestibility of cooked and raw egg protein in humans as assessed by stable isotope techniques. J Nutr 128, 1716-1722.

43. Yoshino K, Sakai K, Mizuha Y, et al. (2004) Peptic digestibility of raw and heat-coagulated hen's egg white proteins at acidic pH range. Int J Food Sci Nutr 55, 635-640.

44. Van der Plancken I, Van Remoortere M, Van Loey IA, et al (2003) Heat-induced changes in the susceptibility of egg white proteins to enzymatic hydrolysis: A kinetic study. J Agric Food Chem 51, 3819-3823.

45. Van der Plancken I, Delattre M, Indrawati, et al. (2004) Kinetic study on the changes in the susceptibility of egg white proteins to enzymatic hydrolysis induced by heat and high hydrostatic pressure pretreatment. J Agric Food Chem 52, 5621-5626.

46. Valle-Riestra J \& Barnes RH (1970) Digestion of heatdamaged egg albumen by the rat. J Nutr 100, 873-882. 